\title{
International Entertainment Incentives: Strategic Choices in a Global Market
}

\author{
Glenda Cantrell Williams \\ The University of Alabama, Tuscaloosa, United States \\ Daniel Wheatcroft \\ Shoot to Thrill Productions, Los Angeles, United States
}

\begin{abstract}
Although business incentives in general have not been proven to be as economically sound as once expected, the United States and other countries still use them to attract the business of entertainment. Although there are some common elements, the overall approach to incentives varies-as does their effectiveness. The majority of the United States has opened their coffers to incentives, and many other countries have as well. This paper looks at the present standing of international entertainment incentives and opens the future of research in this growing area. The analysis shows that international incentives are not only designed to stimulate job development, but also advance the culture of a country or region. In context, this paper shows that these two goals are counter-productive and recommends that governments focus on industry creation and jobs.
\end{abstract}

Keywords: incentives, film, entertainment, international

\section{Introduction}

In a global market, competition is the driving force. For the entertainment industry, production competition comes in the form of film incentives: tax credits or cash rebates for selecting a specific state, country, or locale. This paper will examine the current state of international film incentives, and how specific and strategic moves impact the entire process.

\section{Literature Review}

\section{Business Literature}

Incentives are defined as "all measures that provide explicitly for a more favorable tax treatment of certain activities or sectors compared to what is granted to general industry” (Klemm, 2010, p. 315). This can come in many forms, from tax rebates to cash grants to tax credits, etc.. In the United States, incentives are as varied as the number of states themselves; incentives are most often used to lure companies or businesses from another state or location. Internationally, most countries use some incentives, but they are especially popular in developing countries (Klemm, 2010, p. 316). Klemm argues that this is probably not surprising, given their perception as a development tool, and given that developing economies are often hampered by structural

Glenda Cantrell Williams, Ph.D., associate professor and Chair at the University of Alabama.

Daniel Wheatcroft, Producer, President and CEO of Shoot to Thrill Productions.

Correspondence concerning this article should be addressed to Glenda Cantrell Williams, Box 870152, Tuscaloosa, AL, 35487, United States. E-mail: glenda.williams@ua.edu. 
weaknesses, for which they may wish to compensate by offering incentives. Some incentives, such as tax holidays, are almost exclusively a developing economy phenomenon (Klemm, 2010, p. 316).

However, there is little evidence to suggest that business tax incentives, in general, are as effective as politicians want to believe. A study by Peters and Fisher (2004) argues that the basic expectation of tax incentives - to create jobs for targeted people in targeted areas - is an unsubstantiated claim (Peters \& Fisher, 2004, p. 35). Their metareview of business incentive literature suggests that economic development is not substantially aided by incentives. Rather, although incentives can be somewhat revenue positive at the local level, they are generally revenue negative at the state level—in fact, "states will often end up paying the costs" for what one locale achieved (Peters \& Fisher, 2004, p. 35). Peters and Fisher instead called for a radical departure from current policy ideas; acknowledging, at the same time, that public officials are over-committed to the status quo (Peters \& Fisher, 2004, p. 35). Needed change cannot take place when the leadership believes in the old ideas.

A more recent study concurs. Klemm states that "In many cases, previous skepticism about tax incentives seems warranted, and advice against their rampant use appears appropriate” (Klemm, 2010, p. 333). He added that incentives seem rational in principle, but "In practice, however, it may be difficult to achieve such an outcome, because of the many disadvantages of existing tax incentives and difficulties in their administration” (Klemm, 2010, p. 333). He agreed that competition may drive the incentive structure, but also argued that this is only effective "If there is an increase in aggregate investment and activity, there may be revenue gains from this, such as from additional employment taxes or taxes on input” (Klemm, 2010, p. 323).

In summary, then, there is little published research that recommends tax incentives as solid economic strategy. Although incentives may bring in a business, they do little to stimulate economic development or create targeted jobs. Yet incentives continue to be used because public officials believe in their effectiveness, albeit without proof that the effectiveness is there.

\section{Entertainment Literature}

For the entertainment industry, however, incentives have become a part of the business. Production manager and author Eve Honthaner calls incentives "one of the hottest buzzwords in our industry" (Honthaner, 2010, p. 89) and necessary for film or television production budgeting in today's economy. While noting that there are a number of reasons to select a shooting location, she maintained that "very high on the list of determining factors are the various incentive programs being offered throughout the U.S. and internationally" (Honthaner, 2010, p. 89).

Many experts credit Canada, specifically British Columbia, with beginning the trend of "runaway" production (Gasher, 2002). By courting Hollywood with incentives and a present work crew, British Columbia went from a total of four productions in 1978 to 192 by 2000; direct spending grew from \$12 million to \$1.18 billion (Gasher, 2002, p. 21).

Individual states in the U.S. saw the immense potential in bringing the industry home. In addition to in-state spending, Entertainment Partners notes that "Production of filmed entertainment is especially amenable to incentives because it is highly mobile, environmentally 'clean', capital- and labor-intensive, and effective in promoting tourism” (Chianese, Cordova, \& Rosenfeld, 2011, p. 9). Job training was of special interest: An out-of-work carpenter could learn how to build sets; an out-of-work electrician could learn lighting; local hairstylists and make-up artists could learn how to adapt to the camera. With jobless rates rising, the entertainment industry offered many different employment possibilities. 
As more and more states adopted entertainment incentives, some with mixed results, Hollywood was given more and more options for relocating their productions.

In order to boost local film industries, create jobs, stimulate local economies, and promote tourism, they (the states) appear to be tripping over each other to see which can offer the most desirable incentive package and attract the most film dollars (Honthaner, 2010, p. 90).

As incentives grew more wide-spread, production managers began running incentives in their early budgets for a production in order to select the location. North Carolina, therefore, was able to attract an enormous amount of production; an impact study on Charlotte, NC, showed that the effect was actually revenue positive. Using an IMPAN ${ }^{1}$ model (retrieved from https://implan.com):

...in 2008 the direct impact of the film and video production and distribution industry on the Charlotte Region was to: (1) increase output by over 271 million dollars; (2) support 1,398 full-time equivalent jobs; (3) increase employee and freelancer compensation by over 66 million dollars with average compensations of $\$ 4,678$ per job; and (4) to increase the value added produced in the region by over 84 million dollars. (Connaughton \& Madsen, 2011, p. 24)

These were the kinds of numbers that other states aspired to. Several requirements surfaced through the breakout, however. First, the entertainment industry could only flourish where there was infrastructure already in place, a deep job force already trained, and incentives that were legal and clearly understood by all involved. Second, the state had to have an honest understanding of what they were promising — and the funds to back up the agreement. Third, the industry insisted that the states hire liaisons who had worked in the entertainment industry at some point in their career. ${ }^{2}$

This type of progress does not take place overnight, however. Connecticut, a newer player in the entertainment industry, is still in the examining stages. Although the industry is currently ranked "revenue neutral" in Connecticut, their economists have recommended a continuation of the incentive process due to the insignificant costs required of the state, along with the significant contribution made to education (McMillen, 2011). In fact, the entertainment incentives stimulated a one million dollar investment in education at the state's community college system—all designated for workforce development (McMillen, 2011).

The entertainment industry, though often misunderstood by politicians as "Hollywood," is, in fact, a business - and a prosperous business at that, when approached correctly. As an incentive-driven industry, the entertainment industry succeeds where other industries have failed.

\section{Research Findings}

As the majority of the U.S. states began offering entertainment incentives, other countries outside the US and Canada began developing their own version of incentives. Two primary differences, though, are their consideration of the production company's nationality and the careful consideration of their own culture. This paper will examine these differences and discuss the strategies implemented in this global industry.

\section{Nationality}

One of the primary considerations for whether a company gets an incentive (or, occasionally, a larger incentive) is where their company is based. In the U.S., states tend to favor "resident" companies, or those who

\footnotetext{
${ }^{1}$ IMpact analysis for PLANning (IMPLAN) provides economic impact modeling data for businesses and governments; it began in 1976. For more information, see https://implan.com/.

${ }^{2}$ Hughes, MaryAnn, Vice President, Film and Television Production, Disney Corporation. Personal interview.
} 
set up a company office within the state. Of the 40 states that offer incentives, only eight allow incentives to out-of-state vendors $^{3}$ (Chianese et al., 2011, pp. 16-17). Additionally, when out-of-state companies (non-residents) allow some incentives, they generally are not as large as the resident companies receive. (Chianese et al., 2011, pp. 16-17).

For international incentives, however, the majority of the countries focus not on the location of the company, but on the nationality of the company. Of the 23 countries identified by Entertainment Partners as offering incentives, only five do not require the production company to be owned by a national.

The Dominican Republic, Fiji, Iceland, Malta, and Taipei City, Taiwan all welcome producers of any nationality. All other countries offering incentives require that a local production company be utilized or involved in the production. ${ }^{4}$

In the full sense, this is their answer to economic and workforce development. By focusing on the employment of a local company, owned by a national, these countries eliminate the option of pass-through or temporary companies. While the film may be produced by Hollywood (or any number of other places), involvement of a local company brings money into the local economy in the form of job taxes. Additionally, in order to make this work, the country must have the workforce in place to facilitate these requirements.

\section{Culture}

Part of the reason international countries can require that the use of a local company is the strength of their locales. Indeed, the primary attraction for international locations is their authenticity. Big Ben and the Eiffel Tower, among other international landmarks, are most impressive when actually shot on location. If a film needs Paris or London for a backdrop, then the film needs to be shot in that location. Since the country will provide incentives, under certain requirements, directors react very favorably to the creative opportunity. For the US and Canada, however, incentives are the driving factor, not specific locations, due to current technology. The actual location can vary as long as the incentive is right.

A potential draw-back to the international location, however, is the criteria called the culture test. While culture tests and requirements vary from country to country, they remain a large part of the incentive process, with more than half of the countries requiring a cultural component (see Table 1). Some, such as New Zealand and Singapore, require only that the film place their country in a favorable light. Others, such as Ireland, the Czech Republic, France, and the UK, have a cultural "quiz," “test," or "exam”. These require specific creative criteria, such as a character of that nationality, the language or setting of that nationality, or a historical need to be in that country. Most of the culture quizzes have a point system; a film does not have to have every component, but must reach a certain number of points in order to be eligible for the incentive. For examples of these point systems, see Appendix A and Appendix B.

As noted previously, the most interesting part of the culture requirement is the blending of the incentive (or budget) and the creative process. A film may be required to hire an actor of that nationality, for example, or use subtitles for that portion of the film. This, in essence then, infringes to some degree on the role of the director to make those decisions. Instead, these decisions are made in part by the studio or producer, who wants to take advantage of the generous incentives provided by these countries. While U.S. states may limit

\footnotetext{
${ }^{3}$ California, Kansas, Maryland, Massachusetts, New York, Virginia, West Virginia, and Wisconsin.

${ }^{4}$ One exception: while South Korea requires a South Korean production company involvement, the cities of Busan and Seoul do not.
} 
incentives to residents, there is very little, if any, cultural requirement.

The drawback for the country, however, is limited locale substitution. Countries that require a culture test remove themselves from consideration for films that are not specific to their location. Since the objective of film incentives is to increase workforce and stimulate the economy, placing limitations on the creative process actually has the opposite effect of the incentive. These strategic choices are limiting instead of expanding.

Table 1

International Entertainment Incentives, 2011

\begin{tabular}{|c|c|c|c|}
\hline Country & Resident? & Culture requirement? & Type of incentive \\
\hline Australia & Yes & Yes & Varies \\
\hline Canada & Yes & No & Refundable Tax Credit ${ }^{5}$ \\
\hline Cayman Islands & Yes & No & Cash Rebate \\
\hline Czech Republic & Yes & Yes & Cash Rebate \\
\hline Dominican Republic & No & No & Tax Credit \\
\hline Fiji & No & No & Film Tax Rebate \\
\hline France & Yes & Yes & Refundable Tax Rebate \\
\hline Germany & Yes & Yes & Cash Grant \\
\hline Hungary & Yes & Yes & Sponsor Tax Credit \\
\hline Iceland & No & No & Cash Rebate \\
\hline Ireland & Yes & Yes & Up-Front Funding \\
\hline Israel & Yes & No & Cost Reduction \\
\hline Italy & Yes & Yes & Tax Credit \\
\hline Malta & No & Yes & Cash Grant \\
\hline Mexico & Yes & No & Cash Reimbursement \\
\hline New Zealand & Yes & Yes (content) & Cash Grant \\
\hline Serbia & Yes & No & Cash Rebate \\
\hline Singapore & Yes & Yes (positive content) & Cash Rebate \\
\hline South Africa & Yes & No & Cash Rebate \\
\hline South Korea & Yes $^{6}$ & No & Cash Grant \\
\hline Taipei City, Taiwan & No & Yes & Cash Grant \\
\hline Trinidad \& Tobago & Yes & Yes & Cash Rebate \\
\hline United Kingdom & Yes & Yes & Payable Tax Credit \\
\hline
\end{tabular}

Note. Source: Entertainment Partners, Incentive Solutions, March 2011.

\section{Analysis}

For international countries, the primary use of film incentives seems to be supporting their own workforce and promoting their own culture. In the final analysis, these two goals appear to be counter-productive. Because their culture test limits the types of films to be shot in their country, their long-term support of workforce development is also compromised. These governments must understand that requiring productions to pass a culture test will not assist their goal of economic growth or workforce development. Instead, their country will be limited to only the productions that absolutely need the backdrop of their specific country. For a country to

\footnotetext{
5 Exceptions are for Alberta, which gives a cash grant, and Yukon, which provides a "Spend, Travel, and Training” rebate.

${ }^{6}$ Exceptions are for Busan and Seoul, which have no restrictions on nationality.
} 
develop their entertainment industry into an economic engine requires multiple projects, lining up one after the other to sustain job development and growth. Occasional projects will not meet this need.

The U.S. with the most successful incentive models has the primary goal of creating and sustaining entertainment jobs (Williams \& Wheatcroft, 2013). To reach that goal, consistency is a key building block. Cultural components will certainly promote the accomplishments of a nation or people-but it will not create jobs.

While economic studies have looked at film incentives in some US states, research in international film incentives is just beginning. Future research should compare the benefits of countries requiring a culture component with those who do not. The difficulty with this research, of course, is that different countries provide incentives in different ways, making a direct comparison difficult at best.

It should be noted that film incentives, and the country or state offering them, experience changes on a regular basis. While this information was correct at the time this paper was written, the industry changes almost as rapidly as the technology needed to generate it. Every effort was made to procure up-to-date information.

\section{Conclusions}

As long as there is competition for the business of entertainment, incentives will remain a vital part of the industry. Research determining the effectiveness of film incentives—and analyzing the requirements—will help countries better attract the business of entertainment in the global marketplace.

\section{References}

Chianese, J., Cordova, M., \& Rosenfeld, B. (2011). EP incentive solutions: The essential guide to U.S. \& international production incentives. Burbank, CA: Entertainment Partners.

Connaughton, J. E., \& Madsen, R. A. (2011). The economic impact of the film and video production and distribution industry on the Charlotte regional economy. Journal of Business \& Economics Research, 9(4), 15.

Czech Film Commission. $\quad$ (2011). Retrieved from http://www.filmcommission.cz/doc/FISP-Summary-Cultural-Test-Czech-Film-Commission.pdf

Gasher, M. (2002). Hollywood North: The feature film industry in British Columbia. Vancouver: University of British Columbia Press.

Honthaner, E. L. (2010). The complete film production handbook. Burlington, MA: Focal Press.

Irish Film $\quad$ Board, $\quad$ Culture $\quad$ Test. $\quad$ (2011). $\quad$ Retrieved from http://www.irishfilmboard.ie/financing_your_film/Section_481_Cultural_Test/29 Accessed December 2011

Klemm, A. (2010). Causes, benefits, and risks of business tax incentives. International Tax Public Finance, 17, 315-336.

McMillen, S. (2011). The economic impacts of film tax credits. REMI Webinar. Retrieved from www.remi.com>Events

Peters, A., \& Fisher, P. (2004). The failures of economic development incentives. Journal of the American Planning Association, $70(1), 70$.

Salama, M. (2009). State film tax incentives and the related potpourri of federal income tax and tax accounting considerations. The Tax Lawyer, 62(4), 1085-1112.

UK Film Council (2011). Retrieved from http://www.ukfilmcouncil.org.uk/culturaltestpoints

Williams, G. C., \& Wheatcroft, D. (2013). The economics of entertainment: Succeeding at the state level. International Journal of Business and Social Science, 4(12), 1-5. 


\section{Appendix A: Ireland ${ }^{7}$}

Financing your Film/Tax Incentives/

Section 481 Cultural Test

All projects that are put forward to qualify for Section 481, the Irish tax incentive for film and television, are analysed by the Department of Arts, Sport and Tourism and must meet three of the following cultural test criteria:

(1) The project is an effective stimulus to film making in Ireland, and is of importance to the promotion, development and enhancement of creativity and the national culture-through the medium of film, including, where applicable, the dialogue/narration is wholly or partly in the Irish language or the production of a full Irish-language version of the film is included as part of the total budget for the film.

(2) The screenplay (or, in the case of a documentary film, the textual basis) from which the film is derived is mainly set in Ireland or elsewhere in the EEA.

(3) At least one of the principal characters (or documentary subjects) is connected with Irish or European culture.

(4) The storyline or underlying material of the film is a part of, or derived from, Irish or European culture and/or heritage; or, in the case of an animation film, the storyline clearly connects with the sensibilities of children in Ireland or elsewhere in the EEA.

(5) The screenplay (or textual basis) from which the film is derived is an adaptation of an original literary work.

(6) The storyline or underlying material of the film concerns art and/or an artist/artists.

(7) The storyline or underlying material of the film concerns historical figures or events.

(8) The storyline or underlying material of the film addresses actual, cultural, social or political issues relevant to the people of Ireland or elsewhere in the EEA; or, in the case of an animation film, addresses educational or social issues relevant to children in Ireland or elsewhere in the EEA.

\section{Appendix B: Czech Republic ${ }^{8}$}

Cultural Test-Summary

The Project must score a minimum of four points from cultural criteria, and receive a minimum of 23 points overall, out of a possible total of 46 points. All point allocations shall be reviewed by a Czech industry Council.

Part 1-Cultural Criteria (max 16 points)

The project must score a minimum of four points from cultural criteria. These points may be obtained by fulfilling two of the eight cultural criteria, in full, or may also be met by partial fulfillment of three or four criteria. Fractional points may not be awarded but applicants may score zero, one or two points for each of the cultural criteria:

(1) Storyline/screenplay/central theme of the film is based on events that are a part of Czech or European culture/history/mythology/religion. This criterion refers to productions that are based on incidents being part of traditional Czech or European culture/history/mythology/religion.

$0-2$ points

(2) Film is based on a character/personality from Czech/European culture history/society/religion. This criterion refers to productions that are based on a well known character/personality which plays a significant role in the story.

$0-2$ points

\footnotetext{
${ }^{7}$ Source: Irish Film Board, Culture Test. Retrieved from http://www.irishfilmboard.ie/financing_your_film/Section_ 481 Cultural Test/29.

8 Source: Czech Film Commission. Retrieved from http://www.filmcommission.cz/doc/FISP-Summary-Cultural-TestCzech-Film-Commission.pdf
} 
(3) Storyline of the film is connected with a European setting/place/location/architectural or cultural setting.

$0-2$ points

(4) Storyline/script/central theme of the film is based on a literary work or adapted from another artistic discipline (fine arts, music, etc.) of cultural importance.

$0-2$ points

(5) Storyline/script/central theme of the film focuses on current cultural/sociological/political themes in Czech or European society.

0-2 points

(6) Film reflects important Czech or European value(s), such as cultural diversity/solidarity/equality/protection of minorities or human rights/tolerance/environmental protection/respect for cultural or family traditions.

0 -2 points

(7) Film focuses on Czech/European culture/identity or Czech/European customs and traditions.

0 -2 points

(8) Storyline/script/central theme of the film is based on current or historical events affecting European/Czech society This criterion refers to productions that are based on current or historical incidents having influence on contemporary European/Czech society.

$0-2$ points 